\title{
EXPERIMENTAL ANALYSIS OF DESICCATION CRACK PROPAGATION IN CLAY LINERS1
}

\author{
Carol J. Miller, Hong Mi, and Nazli Yesiller
}

\begin{abstract}
A laboratory investigation on a scaled model of a landfill liner was conducted to provide data regarding the occurrence and extent of desiccation cracking of prototype liners. The crack intensity factor, CIF, was introduced as a descriptor of the extent of surficial cracking. CIF is defined as the ratio of the surface crack area $A_{c}$, to the total surface area of the clay liner, $A_{t}$. $A$ computer aided image analysis program was used to determine CIF values from scanned photographs of the desiccation process. The variation of the CIF was related to duration of drying and measured soil moisture suctions.

The soil of this investigation experienced significant cracking, with crack widths approaching $10 \mathrm{~mm}$ in the first drying cycle and penetration through the entire $16 \mathrm{~cm}$ thickness. Crack propagation was limited to a very intense period of the desiccation process. Nearly 90 percent of the crack development occurred during a 19 hour time period, although the total duration of the desiccation cycle was approximately 170 hours. The soil moisture suction changed by only 2 bars during the period of rapid crack growth, although it changed by more than 40 bars during the period of reduced growth.

(KEY TERMS: soil liners; clays; desiccation cracks; geo-environmental engineering.)
\end{abstract}

\section{INTRODUCTION}

Historically, land disposal has been the most commonly used method of waste disposal. Even now, landfills continue to accept nearly 75 percent of the municipal waste generated in the United States. Landfills accept a variety of wastes that could contain a mixture of organic and inorganic hazardous constituents. Therefore, poorly designed landfills and migration of leachate from the landfills pose a serious environmental threat.

Federal and local regulations govern the design and permitting of containment facilities for the land disposal of solid and hazardous waste. In these regulations, primary reliance is placed on the landfill liner system as the ultimate barrier against leakage of the waste to the surrounding environment. The value of the hydraulic conductivity of the barrier liner is used as the principal indicator of it's containment potential. However, numerous observations of leachate plumes downgradient of landfills have illustrated that leakage occurs in spite of the existing design regulations (Assmuth, 1992; Goodall and Quigley, 1977; Lesage et al., 1993).

Clay soils are commonly used in the construction of landfill liners. Clay soils are also the primary component of other environmental barriers, including slurry walls for containment of contaminated groundwater and pond liners for the storage of liquid wastes. Previous investigations have shown that the performance of these barriers is affected by desiccation and subsequent cracking of the clay soil (Miller, 1988; Montgomery and Parsons, 1989; Benson and Daniel, 1994). Other failure mechanisms involving clay liners include syneresis cracking (Mundell, 1986) and freeze/thaw cracking (Erickson et al., 1994). Cracking leads to a decrease in the containment function of the liner, which can result in an increase in infiltration of surface water into the containment system or migration of the contained liquids into surrounding soils and groundwater. Both effects jeopardize the integrity of the containment system and, thus, the environmental quality of the surrounding subsurface.

The presence of cracks may alter predicted contaminant concentrations due to bypass flow, resulting in increased transport rates and modifications to adsorption and other nonconservative processes (Freeze and Cherry, 1979). Desiccation cracks are also important 
in agricultural applications. The movement of pesticides and fertilizers to the root zone, as well as the efficiency of irrigation operations are impacted on by the presence of desiccation cracks and other forms of macropores (Prendergast, 1995).

The determination of the crack geometry is required for characterizing various phenomena associated with desiccated soils. Bosscher and Douglas (1988) emphasized the need for accurate description of the spatial characteristics of joint systems including desiccation cracks. These characteristics were required for groundwater models to determine flow in fractured soils and for geotechnical models to determine the strength parameters of fractured soils. In addition, knowledge of the spatial characteristics of jointed systems is required in environmental applications to accurately model dispersion of contaminants (Domenico and Schwartz,1990). Benson and Daniel (1994) also emphasized the need for information regarding the geometry of macropores for porous media flow models.

In this research, a laboratory model of a compacted clay liner was used to investigate the development and progression of desiccation cracking. The surface geometric features of cracks developing as a result of wetting and drying cycles were monitored and relationships were developed between the extent of cracking and the water potential of the clay liner. The research implications are limited to the specific soils analyzed in this investigation. Ongoing and further research will facilitate the development of applications to fine grained soils with varied characteristics, which will allow the development of generalized and specific predictive models of crack geometry for known soil types, placement conditions, and climatological history.

\section{BACKGROUND}

\section{Crack Theory}

Although the mechanisms controlling cracking are very complicated, there has been some progress in developing theoretical models of the process. It is known that surface tension effects at air-water-solid contacts inside the soil generate negative pore water pressures (positive suctions) in the unsaturated soil. The matrix suction may result in soil contraction, and ultimately soil shrinkage and cracking. This shrinkage produces vertical cracks below exposed horizontal drying surfaces. The depth of the cracks increases gradually, as desiccation of the soil deposit progresses. The volume change is directly related to the shrinkage limit. For plasticity index (PI) values greater than
35, excessive shrinkage can be expected (Daniel, 1991).

Morris et al. $(1992 ; 1994)$ offered analytical solutions to predict the depth of cracks for the case of a steady state suction distribution from ground surface to water table. The suction was assumed a maximum value at ground surface and zero at the water table. Fredlund and Rahardjo (1993) presented another analytical solution for depth of cracking as a function of depth to groundwater table, Poisson s ratio, soil density, matric suction, and soil elastic moduli. They assumed a linear matric suction profile extending from the groundwater table to the ground surface.

These analytical solutions have limited applicability. Many engineering applications involve layered soils, far removed from the water table, having nonlinear suction profiles, and anisotropic behavior. The most obvious example of such an application is the soil liner of a landfill. This study provides an analysis of desiccation cracking in a compacted clay soil simulating a landfill liner. The results of this study provide an empirical basis for regulatory criteria involving liner thickness, in addition to providing a better understanding of the conditions promoting desiccation cracking.

\section{Quantification of Crack Dimensions}

Most data available regarding the geometry of desiccation cracks are related to landfill applications. Basnett and Brungard (1992) observed cracks resulting from desiccation on the side slopes of a clay liner during landfill construction. The cracks were $13 \mathrm{~mm}$ to $25 \mathrm{~mm}$ in width and extended to $0.30 \mathrm{~m}$ depth. Miller and Mishra (1989) observed uniformly distributed desiccation cracks during their field investigation of landfill clay liners. The cracks exceeded 10 $\mathrm{mm}$ in width and some penetrated the entire depth $(0.30 \mathrm{~m})$ of the compacted clay layer. Montgomery and Parsons (1989) observed desiccation cracking at test plots simulating covers constructed at a landfill in Wisconsin. Subsequent to three years of exposure, the upper 0.20 to $0.25 \mathrm{~m}$ of the compacted clay plots had become desiccated, with crack widths exceeding 13 $\mathrm{mm}$. They reported maximum crack depths of $1.0 \mathrm{~m}$ at a number of locations in the test plots. Corser and Cranston (1991) reported observations of cracks down to $0.10 \mathrm{~m}$ deep within compacted cover sections from a test fill in an arid part of California.

Morris et al. (1992) reported that macrocracks were produced by the growth of microcracks under tensile loading at crack tips. The uniform tensile stress (transverse to the crack) which causes a crack of length 2A to propagate was found to be inversely proportional to the square root of $A$. They also reported 
that the suction at the crack tip was inversely proportional to the radius of capillaries and hence to particle size. Comparison of the above two relationships for tensile stress and matric suction in terms of crack length $A$ shows that soil suction related macrocracks are more readily produced in fine-grained soils than in coarse grained soils. This is because fine grained soils have smaller intergranular voids which can trap larger volumes of pore air per unit area per volume than coarser soils.

Morris et al. (1992) explained that matric suctions in uncracked soils produce compressive stresses between the particles. Therefore, conditions for crack propagation are most favorable at the ground surface where self weight stresses are zero and matric suctions are maximum. They show that the depth of cracks is ultimately constrained by the increasing stresses due to soil self weight, and their surficial length is limited by intersection with other cracks.

\section{EXPERIMENTAL SET-UP}

The laboratory investigation was designed to provide qualitative information and quantitative data on the physical processes involved in desiccation cracking of a compacted fine-grained soil under wetting and drying cycles. The experimental apparatus included: a soil tank, rainfall simulation system, drying system, drainage system, surface crack recording system, and water potential measuring system (Figure 1). The primary component was the steel reinforced Plexiglas tank, of dimensions $1.5 \mathrm{~m}$ (width), 1.0

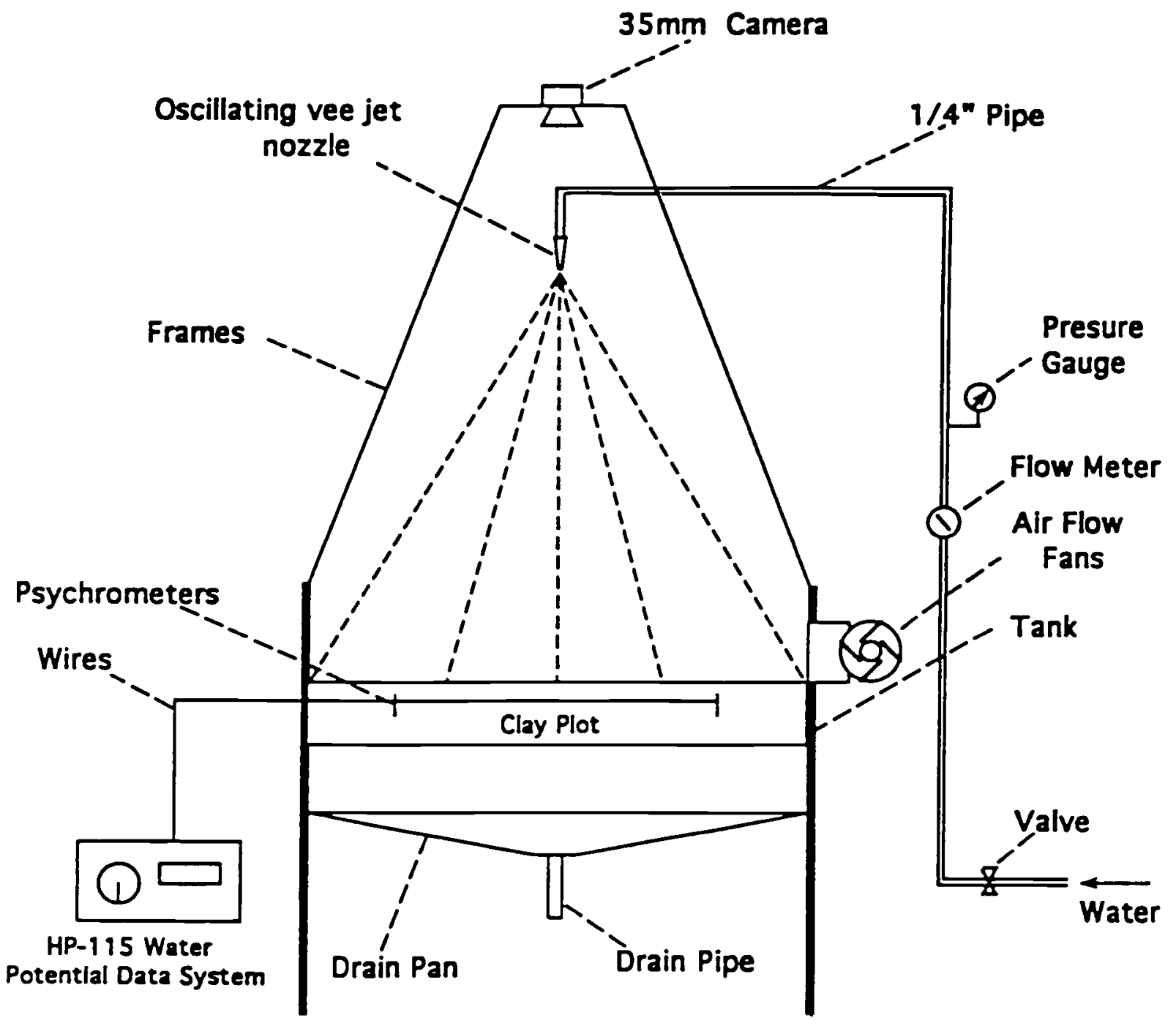

Figure 1. Components of the Experimental System for Desiccation Crack Development and Analysis. 
$\mathrm{m}$ (length) and $0.5 \mathrm{~m}$ (depth). Three blowers were fixed on the wall of the tank to simulate wind action on the soil surface and increase the rate of soil desiccation. A rainfall simulation system consisting of pipe, regulator, flow meter, pressure gauge, and water spraying nozzle was positioned over the tank. The oscillation of the nozzle was controlled electronically to provide complete and regular coverage of the entire tank. Variable rainfall intensities were simulated by changing the flow nozzle. A drainage system beneath the tank was equipped to collect and measure leakage via the compacted clay. These leakage measurements were used to calibrate a hydraulic model of flow through desiccated liners ( $\mathrm{Mi}, 1995)$. A $35 \mathrm{~mm}$ automated camera was mounted $1.2 \mathrm{~m}$ above the tank to record the entire process of crack initiation and propagation. Wescor Model P55 psychrometers were embedded inside the soil and were connected to a Wescor Model HP-115 Water Potential Data System for automatic measurement of the water potentials.

Psychrometers were selected for the soil water potential measurements of this study because very dry conditions were expected. In these applications, tensiometers are inappropriate due to air entry problems. Psychrometers have successfully measured insitu suction values as high as 30 atmospheres and appear to be the best monitoring device for very dry soil conditions, where other methods may be limited (Hoffman et al., 1972). Psychrometers provide measurements of soil water potential using a relationship between soil water potential and relative humidity. Psychrometers are composed of a porous bulb to sample the relative humidity of the soil, a thermocouple, a heat sink, a reference electrode, and related circuitry. Calibration is required for each psychrometer unit before it is used to measure soil water potential. Psychrometers are very sensitive to temperature fluctuations and require correction for even minor temperature changes. A layer of six evenly spaced psychrometers were placed during the liner compaction process, at mid-depth of the clay liner.

\section{MATERIALS}

The clay soil used in this study was obtained from a borrow area used for construction of a liner for a landfill in metropolitan Detroit, Michigan. The soil is classified as a silty clay (CL-ML) using the Unified Soil Classification System (USCS). The properties of the soil are presented in Table 1.

The mineralogical composition of the clay, silt, and sand fractions (Table 2) was determined by Salim (1994) using a Rigaku RU200 X-ray rotating anode powder mount diffractometer. The clay fraction of the soil consists mostly of illite ( 63 percent by weight). The second dominant clay mineral is kaolinite (11 percent by weight). These minerals contribute to the low plasticity of the soil. This soil is representative of soils used for landfill liner construction in Michigan (Salim, 1994). Therefore, it is expected that the results of the investigation can be applied at the regional scale.

TABLE 1. Clay Liner Properties (Salim, 1994).

\begin{tabular}{llc}
\multicolumn{1}{c}{ Property } & \multicolumn{1}{c}{ Standard* } & Value \\
\hline Specific Gravity & ASTM D 854-92 & 2.70 \\
Hydraulic Conductivity, cm/sec & ASTM D 5084-90 & $1.07 \times 10^{-8}$ \\
Particle Size Analysis & ASTM D 422-63(90) & \\
$\quad$ Percent Sand & & 20 \\
$\quad$ Percent Silt & & 25 \\
$\quad$ Percent Clay & ASTM D 4318-93 & 55 \\
Atterberg Limits & & 22.6 \\
$\quad$ Liquid Limit (percent) & & 6.2 \\
$\quad$ Plasticity Index (percent) & & 13.5 \\
Optimum Moisture Content & & \\
$\quad$ (percent) (Standard Proctor) & ASTM D 698-91 & 19.3 \\
Maximum Dry Density, kN/m ${ }^{3}$ & & \\
$\quad$ (Standard Proctor) & ASTM D 698-91 & \\
\hline
\end{tabular}

*The complete citation for each standard (ASTM, 1994a-e) is provided in Literature Cited.

TABLE 2. Mineralogical Analysis of Soils (Salim, 1994).

\begin{tabular}{|c|c|c|}
\hline Soil Fractions & Minerals & $\begin{array}{c}\text { Weight } \\
\text { Percentage }\end{array}$ \\
\hline \multirow[t]{7}{*}{ Clay } & Chlorite & 8 \\
\hline & Illite & 63 \\
\hline & Hornblende & 3 \\
\hline & Kaolinite & 11 \\
\hline & Microcline & 6 \\
\hline & Quartz & 5 \\
\hline & Plagloclase & 4 \\
\hline \multirow[t]{6}{*}{ Silt } & Chlorite & 3 \\
\hline & Illite & 3 \\
\hline & Quartz & 56 \\
\hline & Albite & 6 \\
\hline & Calcite & 21 \\
\hline & Dolomite & 11 \\
\hline \multirow[t]{3}{*}{ Sand } & Quartz & 90 \\
\hline & Calcite & 7 \\
\hline & Dolomite & 3 \\
\hline
\end{tabular}


The experimental procedure consisted of two main steps: (1) soil preparation and compaction and (2) simulation of wetting/drying cycles.

\section{Compaction}

The soil compaction required special attention to ensure uniformity in density and moisture conditions throughout the test liner. Prior to compaction, the large soil clods were broken down into smaller units (maximum equivalent diameter less than $1.0 \mathrm{~cm}$ ). The soil was wetted approximately to the optimum moisture content ( 1 percent). The wetted soil was left in sealed boxes for two days of soaking to achieve uniform moisture absorption. The loose soil was then placed in the experimental tank and manually compacted using a square steel pad of area $25 \mathrm{~cm}^{2}$ and weighing $96 \mathrm{~N}$. The pad was lifted approximately 60 $\mathrm{cm}$ and dropped freely to the soil surface. The specific values for lift height and number of blows (approximately 70) were determined by equating the compaction energy per unit area of this method to the standard proctor compaction test. The clay soil was compacted in the tank to a depth of $16 \mathrm{~cm}$, which is within the range of the recommended lift thickness for landfill liner construction (Bagchi, 1990). Following compaction, the dry density and water content were measured to be $18 \mathrm{kN} / \mathrm{m}^{3}$ and 11.01 percent, respectively. The water content of the soil was approximately 2 percent dry of optimum moisture content. The relative compaction (as a ratio of compaction density to maximum dry density) was 93 percent.

\section{Wetting and Drying Cycles}

Soil moisture suction and crack propagation were analyzed for three distinct periods of wetting and drying. The first period, termed compaction-dry, corresponds to the time between the completion of compaction to fully dry conditions (defined as the onset of a stable soil pore water suction). Rainfall was then applied to the dry soil. The period between the fully dry condition and infiltration of the ponded water from the simulated rainfall was termed the dry-wet period. The soil tank was sealed with a glass cover during the infiltration phase to prevent evaporation of moisture. The last period of a cycle was the wet-dry period. The cover was removed at the beginning of the wet-dry period which began with the end of the second period and terminated with the development of fully dry conditions.

\section{Water Potential Measurements}

The water potential of the soil liner throughout the wetting and drying process is shown in Figure 2. The water potential decreased during the compaction-dry period from $\mathbf{- 2 2 . 1}$ bars to $\mathbf{- 5 8 . 3}$ bars. During the drywet period, the water potential values increased from -58.3 bars to -6.0 bars. Finally, during the wet-dry period the water potentials decreased to -60.7 bars, which was the driest condition achieved.

\section{Crack-Intensity-Factor (CIF)}

The geometric features of cracks, such as width, depth, and surface area, are important parameters, because they influence both the soil hydraulics and mechanics. The crack intensity factor (CIF) was introduced as a descriptor of the extent of surficial cracking. CIF is defined as the time-variable ratio of the surface crack area, $A_{c}$, to the total surface area of the clay, $A_{t}$. A computer aided image analysis program was used to determine CIF values from scanned photographs of the desiccation process.

Figure 3 illustrates key aspects of the CIF. Figure 3a shows the CIF variation with time for the wet-dry period (C-D of Figure 2), while Figure 3b shows the relation between the CIF and water potential for the same period. From Figure 3a, the CIF remained close to its initial value of zero for approximately 17 hours. Subsequently, the CIF increases rapidly for a period of approximately 19 hours of drying. At the end of the 36 hours, the CIF approaches a steady state of approximately 5.5 percent. Figure $3 \mathrm{~b}$ illustrates that the surface crack area increases rapidly when the soil water potential changes from 6.0 to 7.9 bars. At water potentials higher than that, crack growth increases at a much smaller rate. Although the water potential increases in a nearly linear fashion during this time period (Figure 2), there is little change in the CIF.

Extensive cracking occurred during the wet-dry period. The propagation of cracks during this period was analyzed in detail and three distinct stages of crack formation were identified. The initial cracking stage encompasses the period following water addition to the time corresponding to crack coverage over the entire surface, or the development of "first-generation" cracks. During the second stage of cracking, initial cracks became wider and deeper, with a few new cracks being formed inside existing polygons. These represent "later-generation" cracks and this stage was termed the "enhanced cracking stage". 


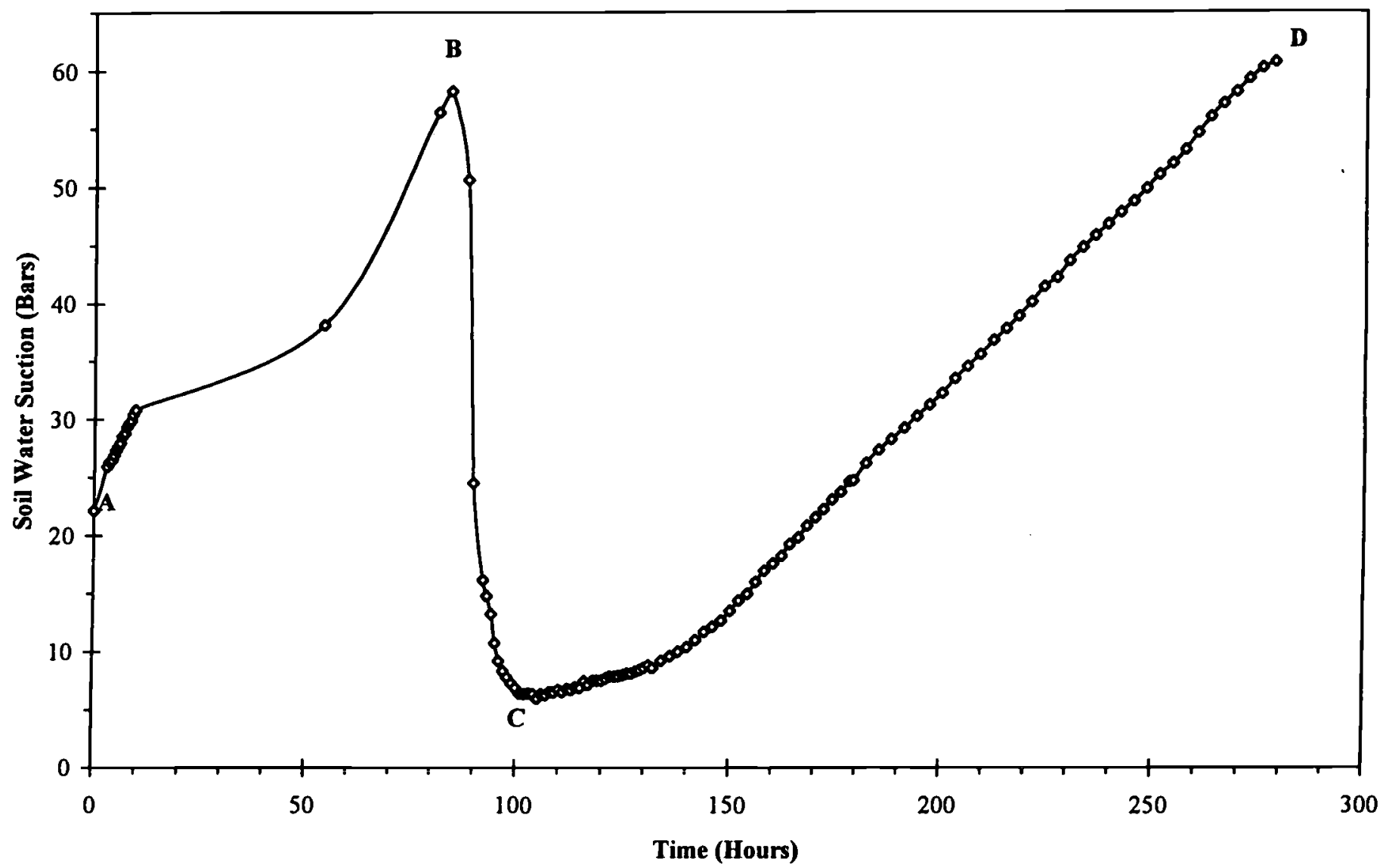

Figure 2. Soil Water Potential Measurements for the Clay Liner:

A-B: Compaction-Dry Period; B-C: Dry-Wet Period; and C-D: Wet-Dry Period.

Crack propagation in the final stage was limited. No major changes in crack formation or physical characteristics were observed during this stage, termed the "stable stage." Table 3 summarizes the variation of time, water potential, and CIF during the three cracking stages of the wet-dry period.

The data of Table 3 indicate a maximum measured water potential of 53.2 bars at a test duration of 168 hours. The psychrometers remained embedded in the soil for several weeks beyond this endpoint. However, the readings from the psychrometers became increasingly erratic. It is likely that at such dry states the necessary equilibrium between psychrometer and soil pore space is not achieved, creating erratic and unpredictable readings. Visual observations confirmed that the maximum CIF during the stable cracking stage, extending for several weeks beyond the 168-hour duration of Table 3 , was limited to approximately 5.5 percent.

It may be possible in the future to use this type of information to predict crack growth based on measured water potentials. Alternatively, numerical models may be used to predict soil water potential based on simulated climatology and hydrology of a site. Using experimental data such as those provided in Table 3, these modeled water potentials could be used to infer the potential for cracking problems in the soil. As an example, the model HELP (Schroeder et al., 1994) is often used to estimate leachate production and leak generation at existing and proposed landfill facilities. As one step in that process, the model estimates the soil water potential in the clay liners of the landfill containment system. If information regarding the cracking/water potential relation is available for the soil used in the landfill liner, it may be possible to assess the adequacy of a proposed landfill design.

\section{Qualitative Observations of Crack Formation}

The behavior of surface cracking was distinctly different in each of the three test periods analyzed. There were no observable cracks on the soil surface immediately following compaction. During the compaction-dry period, limited cracking of the soil 


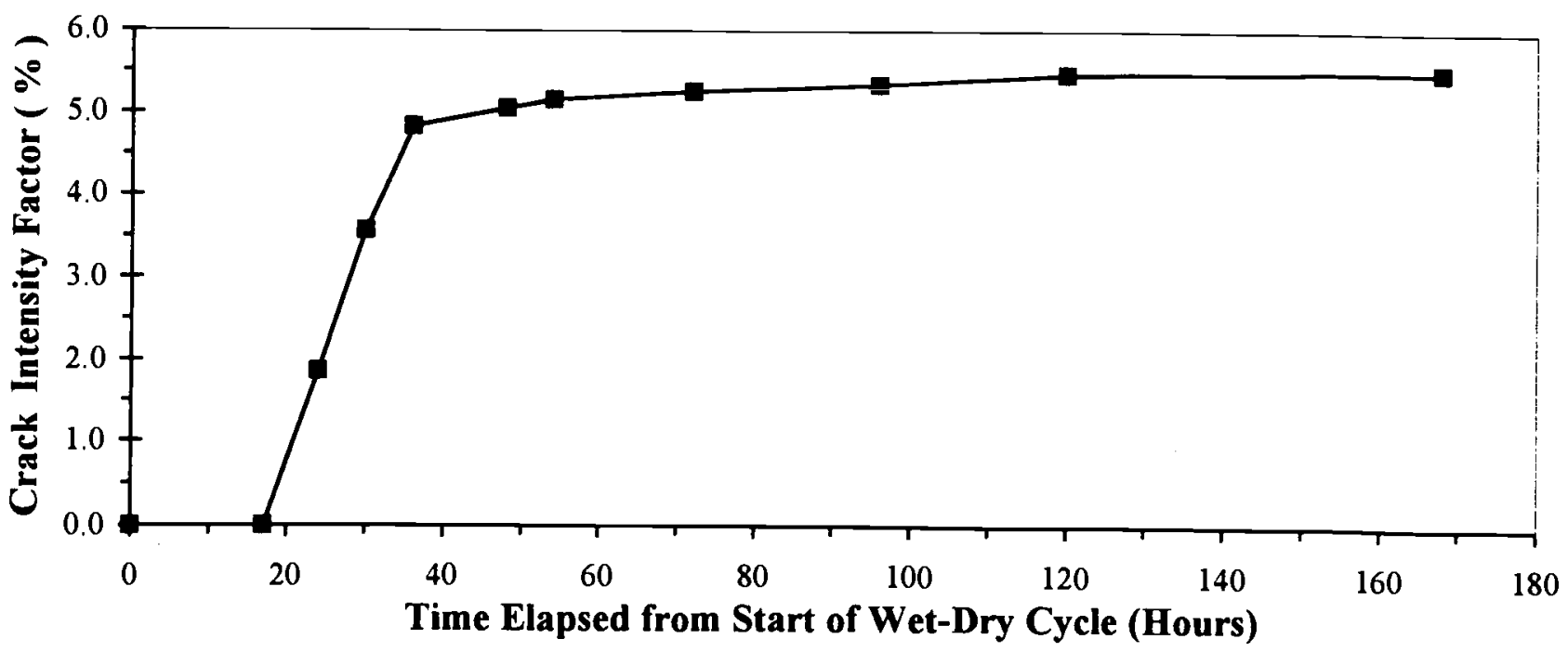

(a)

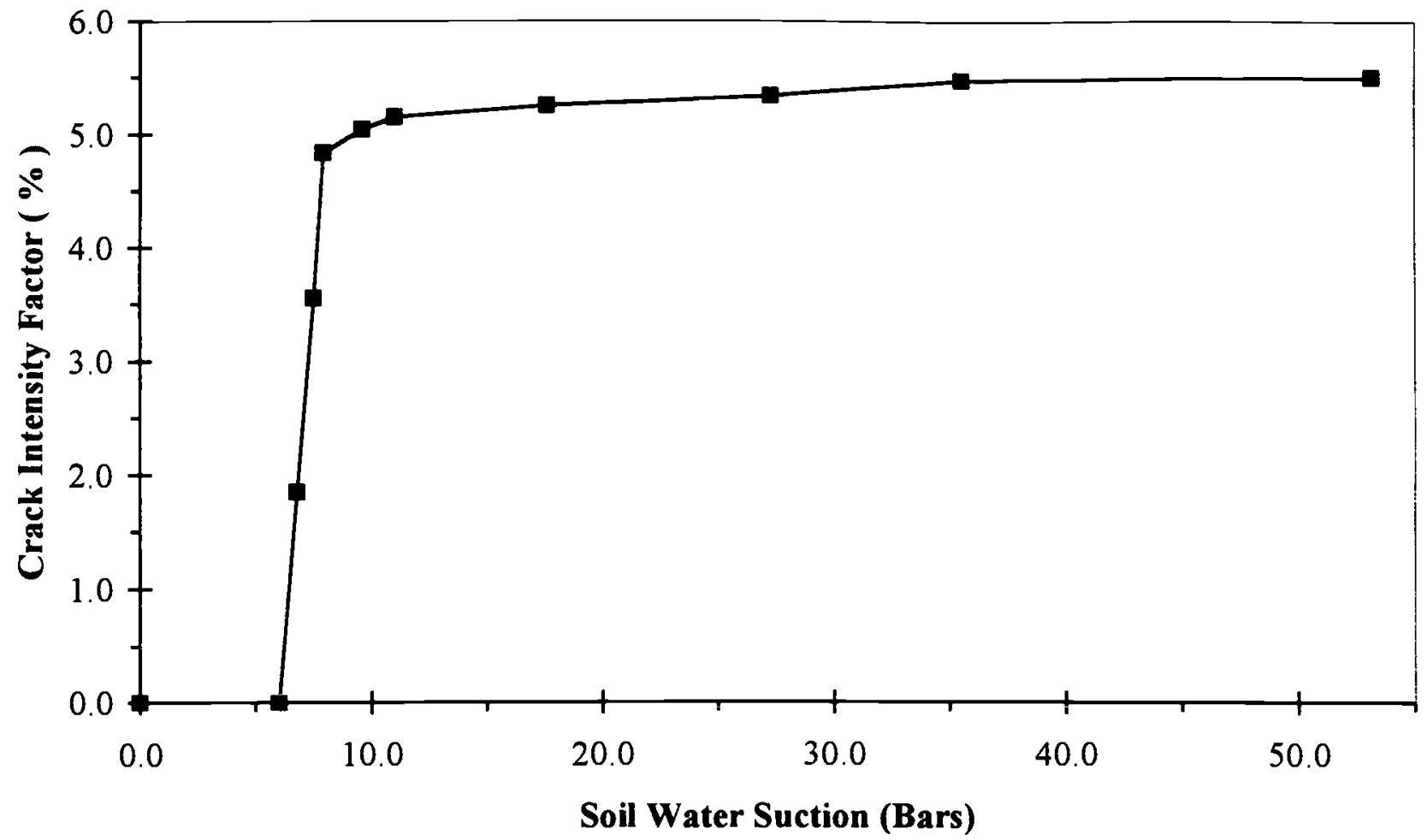

(b)

Figure 3. Crack Intensity Factor (CIF) Analysis for the Wet-Dry Period (a) CIF Variation With Time; (b) CIF Variation With Soil Water Suction.

TABLE 3. Characteristic Features During the Three Stages of Cracking.

\begin{tabular}{cccc} 
Stage & $\begin{array}{c}\text { Time } \\
\text { (hours) }\end{array}$ & $\begin{array}{c}\text { Water Potential } \\
\text { (negative bars) }\end{array}$ & $\begin{array}{c}\text { CIF } \\
\text { (percent) }\end{array}$ \\
\hline Initial Cracking & $17 \sim 36$ & $6.0 \sim 7.9$ & $0.0 \sim 4.8$ \\
Enhanced Cracking & $36 \sim 72$ & $7.9 \sim 17.6$ & $4.8 \sim 5.3$ \\
Stable Cracking & $72 \sim 168$ & $17.6 \sim 53.2$ & $5.3 \sim 5.5$ \\
\hline
\end{tabular}


surface occurred (Figure 4a). The crack pattern was primarily linear, with a few extensions of smaller cracks. During the compaction-dry period, cracks did not penetrate the entire depth of the soil layer. During the $d r y$-wet period, rainfall was simulated. The cracks that had formed during the previous period gradually disappeared due to expansion/swelling of the soil. Extensive cracking occurred during the wet$d r y$ period, with some of the cracks appearing in the same locations as in the dry-wet period. There was significant growth in the crack dimensions during this period. The observed maximum crack widths for the compaction-dry and wet-dry periods were $5.0 \mathrm{~mm}$ and $9.5 \mathrm{~mm}$, respectively. The crack pattern during the wet-dry period was polygonal (Figure $4 \mathrm{~b}$ ), as opposed to the linear nature of the cracks which developed during the compaction-dry period.

Although the quantitative tracking of crack propagation was limited to the first wet-dry cycle (C-D of Figure 2), additional simulated rainfalls were applied, repeating the dry-wet and wet-dry cycles, providing the basis for further qualitative observations. The CIF increased during subsequent wet-dry cycles, with cracks reappearing in the locations of the initial wetdry cycle. In addition, the crack dimensions appeared to increase in proportion to the increased number of wet-dry cycles.

During the $d r y$-wet periods, the rainfall intensity controlled the crack characteristics. For intensities less than $1.0 \mathrm{in} / \mathrm{hr}$, the cracks were closed at the surface and were no longer visible. However, increased intensities resulted in the widening of cracks due to the erosive action of water flow through the cracks.

\section{CONCLUSIONS}

A laboratory investigation of desiccation cracking of a clay landfill liner was completed to provide qualitative and quantitative data regarding crack geometry and to relate cracking to measurable soil properties. Previous studies have suggested that desiccation cracking is not expected to be significant for low plasticity soils and that desiccation cracking is less likely for soils compacted dry of the optimum moisture content (Daniel, 1991). The soil investigated in this study had a low PI and was compacted dry of optimum. However, it experienced significant cracking, with crack widths approaching $10 \mathrm{~mm}$ in the first drying cycle, and crack penetration through the entire $16 \mathrm{~cm}$ thickness of the clay.

The desiccation crack features were highly dependent on the cycle of desiccation being observed. The initial crack pattern was primarily linear with many small branches. Cracks initiated during this cycle did not penetrate the entire depth of the soil layer. Following moisture addition, desiccation was allowed to continue. The cracks which formed after moisture addition developed a polygonal pattern of crack networks and some penetrated the entire liner thickness.

The CIF was introduced to describe the extent of cracking in soils. The visual observation of the cracking process was quantified using the CIF. A significant change in the CIF was observed at the beginning of a drying cycle. However, the CIF stabilized with further increases in soil moisture suction.

Crack propagation was limited to a very intense period of the desiccation process. Nearly 90 percent of the crack development occurred during a 19-hour time period, although the total duration of the desiccation cycle was approximately 170 hours. Cracking commenced when the soil moisture suction reached a value of approximately 6 bars. The soil moisture suction changed by only 2 bars during the period of rapid crack growth, while the soil moisture suction changed by more than 40 bars during the period of reduced growth.

In general, the addition of moisture, via simulated rainfalls, caused partial closing on the surface of the cracks. However, the actual response appeared to be dependent on the rate of moisture application (rate of the simulated rainfall). Large intensity rainfalls led to widening of the cracks with erosion of soil particles.

\section{ACKNOWLEDGMENT}

This research was funded, in part, by the National Science Foundation, Division of Geomechanical, Geotechnical, and Geoenvironmental Systems (Grant No. MSS-9123563).

\section{LITERATURE CITED}

Assmuth, T., 1992. Distribution and Attenuation of Hazardous Substances in Uncontrolled Solid Waste Landfills. Waste Management and Research 10:235-255.

ASTM, 1994a. Test Method for Specific Gravity of Soils. ASTM Standard No. D 854-92, Annual Book of ASTM Standards.

ASTM, 1994b. Test Method for Liquid Limit, Plastic Limit, and Plasticity Index of Soils. ASTM Standard No. D 4318-93, Annual Book of ASTM Standards.

ASTM, 1994c. Method for Particle-Size Analysis of Soils. ASTM Standard No. D 422-63 (1990), Annual Book of ASTM Standards.

ASTM, 1994d. Test Method for Laboratory Compaction Characteristics of Soil Using Standard Effort $\left(12,400 \mathrm{ft}-\mathrm{lbf} / \mathrm{ft}^{3}(600 \mathrm{kN}\right.$ $\left.\mathrm{m} / \mathrm{m}^{3}\right)$ ). ASTM Standard No. D 698-91, Annual Book of ASTM Standards.

ASTM,1994e. Test Method for Measurement of Hydraulic Conductivity of Saturated Porous Materials Using a Flexible Wall Permeameter. ASTM Standard No. D 5084-90, Annual Book of ASTM Standards. 

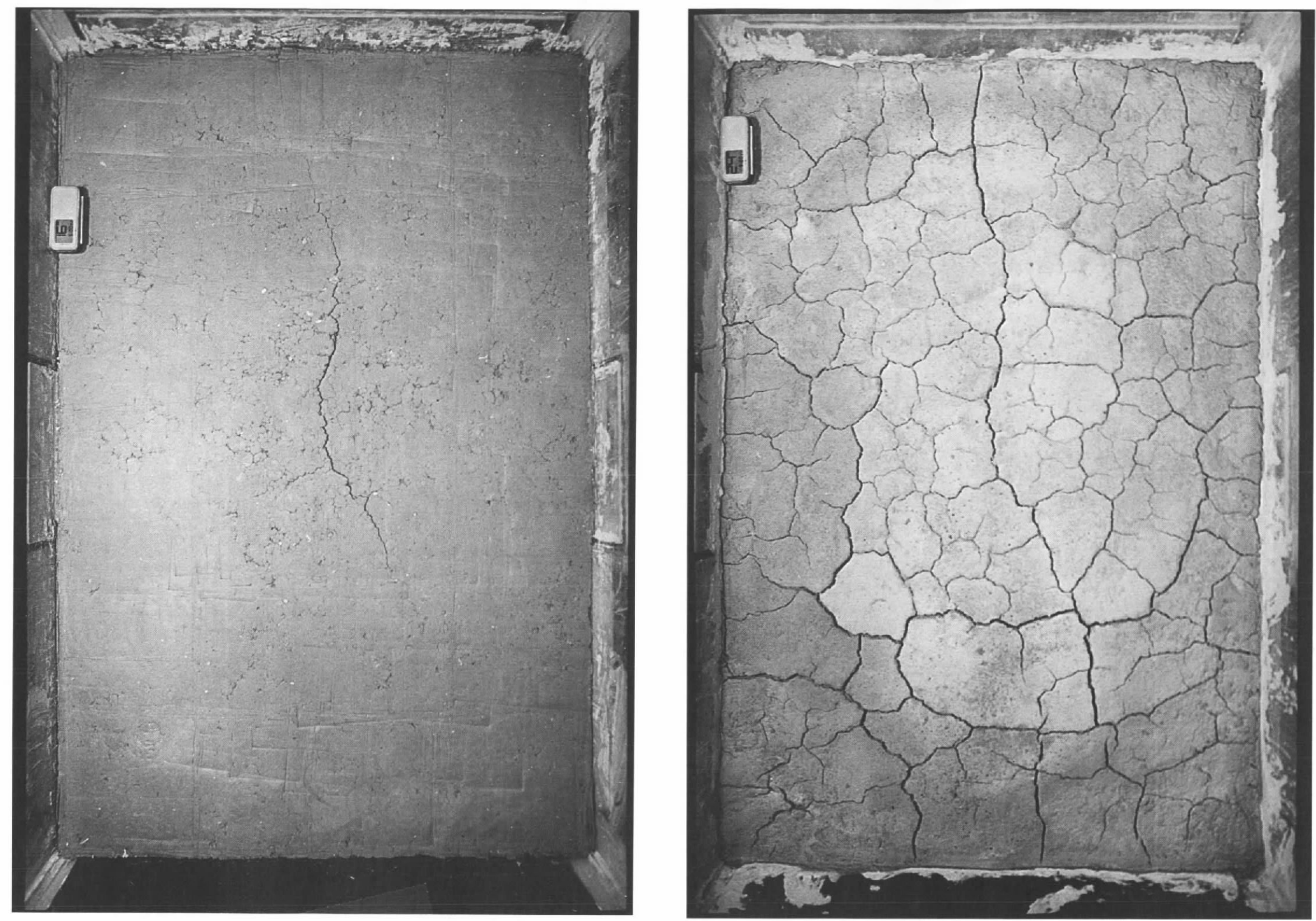

Figure 4. Aerial Photographs of the Crack Network Which Developed in Response to Desiccation (a) Linear Cracking During a Compaction-Dry Period; and (b) Polygonal Cracking During a Wet-Dry Period. 
Bagchi, A., 1990. Design, Construction, and Monitoring of Sanitary Landfill. Wiley-Interscience, New York, New York, 284 pp.

Basnett, C. and M. Brungard, 1992. The Clay Desiccation of a Landfill Composite Lining System. Geotechnical Fabrics Report, Industrial Fabrics Association International, pp. 38-41.

Benson, C. H. and D. E. Daniel, 1994. Minimum Thickness of Compacted Soil Liners: I. Stochastic Models. Journal of Geotechnical Engineering, ASCE 120(1):129-152.

Bosscher, P. J. and E. C. Douglas, 1988. Measurement and Analysis of Jointing Properties in Fine-Grained Soils. Journal of Geotechnical Engineering, ASCE 114(7):826-843.

Corser, P. and M. Cranston, 1991. Observations on Long-Term Performance of Composite Clay Liners and Caps. In: Proceedings of the Conference on Geosynthetic Design and Performance, Vancouver Geotechnical Society, Vancouver, Canada.

Daniel, D. E., 1991. Design and Construction of RCRA/CERCLA Final Covers, Chapter 2: Soils Used in Cover Systems. EPA/625/4-91/025, 145 pp.

Domenico, P. A. and F. W. Schwartz, 1990. Physical and Chemical Hydrogeology. John Wiley and Sons, New York, New York, 824 pp.

Erickson, A. E., E. J. Chamberlain, and C. H. Benson, 1994. Effects of Frost Action on Covers and Liners Constructed in Cold Environments. Seventeenth International Madison Waste Conference, Madison, Wisconsin, pp. 198-220.

Fredlund, D. G. and H. Rahardjo, 1993. Soil Mechanics for Unsaturated Soils. John Wiley and Sons, New York, New York, 517 pp.

Freeze, R. A. and J. Cherry, 1979. Groundwater. Prentice-Hall, Englewood Cliffs, New Jersey, 604 pp.

Goodall, D. C. and R. M. Quigley, 1977. Pollutant Migration from Two Sanitary Landfill Sites Near Sarnia, Ontario. Can. Geotech. Journal 14:223-236.

Hoffman, G., J. Oster, and S. Merrill, 1972. Automated Measurement of Water Potential and Its Components Using Thermocouple Psychrometers. In: Psychrometry in Water Relations Research, R. Brown and B. Van Haveren, (Editors). Utah Agricultural Experiment Station, Utah State University, Logan, Utah, pp. 123-130.

Lesage, S., R. A. McBride, P. M. Cureton, and S. Brown, 1993. Fate of Organic Solvents in Landfill Leachates Under Simulated Field Conditions and in Anaerobic Micorcosms. Waste Management and Research 11:215-226.

Mi, H., 1995. Kinematic Wave Formulation for Flow Through Macroporous Soil. Ph.D. Dissertation, Department of Civil and Environmental Engineering, Wayne State University, Detroit, Michigan.

Miller, C. J., 1988. Field Investigation of Clay Liner Movement. Hazardous Waste and Hazardous Materials 5(3):231-238.

Miller, C. J. and M. Mishra, 1989. Modeling of Leakage Through Cracked Clay Liners-I: State of the Art. Water Resources Bulletin 25(3):551-555.

Montgomery, R. J. and L. J. Parsons, 1989. The Omega Hills Final Cap Test Plot Study: Three Year Data Summary. Presented at the 1989 Annual Meeting of the National Solid Waste Management Association, Washington D.C.

Morris, P. H., J. Graham, and D. J. Williams, 1992. Cracking in Drying Soils. Canadian Geotechnical Journal 29:263-277.

Morris, P. H., J. Graham, and D. J. Williams, 1994. Crack Depths in Drying Clays Using Fracture Mechanics. Fracture Mechanics Applied to Geotechnical Engineering. Special Geotechnical Publication, ASCE 43:40-63.

Mundell, J. A., 1986. Clay Liner/Leachate Compatibility Modeling. Environmental Engineering, Proceedings of the 1986 Specialty Conference, ASCE, New York, New York, pp. 407-413.

Prendergast, J. B., 1995. Soil-Water Bypass and Solute Transport Under Irrigated Pasture. Soil Sci. Soc. of Am. Journal 59(6):1531-1539.
Salim, I. A., 1994. Modeling the Sorption and Transport of Heavy Metals Through Landfill Clay Liners. Ph.D. Dissertation, Department of Civil and Environmental Engineering, Wayne State University, Detroit, Michigan.

Schroeder, P. R., T. Dozier, P. Zappi, B. McEnroe, J. Sjostrom, and R. Peyton, 1994. The Hydrologic Evaluation of Landfill Performance (HELP) Model: Engineering Documentation for Version 3. EPA/600/R-94/168b, U.S. Environmental Protection Agency, Cincinnati, Ohio, 116 pp. 